LA-14299

Approved for public release;

distribution is unlimited.

\title{
Effects of Temperature and Humidity on
} Wilethane 44 Cure 
Los Alamos National Laboratory, an affirmative action/ equal opportunity employer, is operated by Los Alamos National Security, LLC, for the National Nuclear Security Administration of the U.S. Department of Energy under contract DE-AC52-06NA25396.

\section{NAS \\ National Nuclear Security Administration}

This report was prepared as an account of work sponsored by an agency of the U.S. Government. Neither Los Alamos National Security, LLC, the U.S. Government nor any agency thereof, nor any of their employees make any warranty, express or implied, or assume any legal liability or responsibility for the accuracy, completeness, or usefulness of any information, apparatus, product, or process disclosed, or represent that its use would not infringe privately owned rights. Reference herein to any specific commercial product, process, or service by trade name, trademark, manufacturer, or otherwise does not necessarily constitute or imply its endorsement, recommendation, or favoring by Los Alamos National, LLC, the U.S. Government, or any agency thereof. The views and opinions of authors expressed herein do not necessarily state or reflect those of Los Alamos National Security, LLC, the U.S. Government, or any agency thereof. Los Alamos National Laboratory strongly supports academic freedom and a researcher's right to publish; as an institution, however, the Laboratory does not endorse the viewpoint of a publication or guarantee its technical correctness. 
LA-14299

Issued: October 2006

Effects of Temperature and Humidity on

Wilethane 44 Cure

John C. Weigle

- Los Alamos 


\section{Contents}

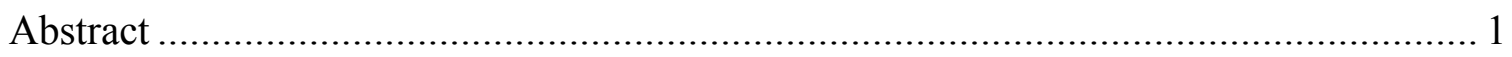

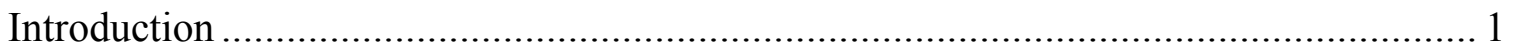

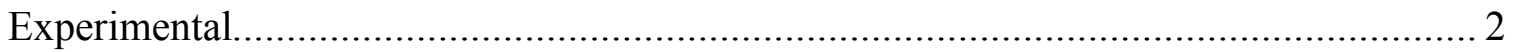

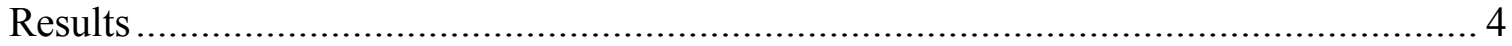

Establishing Environmental Conditions for Wilethane 44 Use...................................... 7

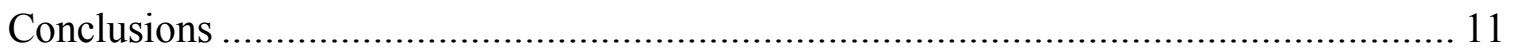

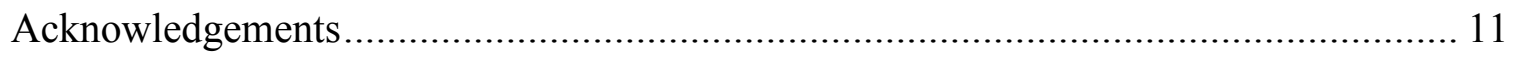

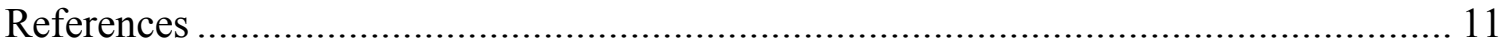

\section{List of Figures}

Figure 1. Cure curves for Wilethane 44 at $\sim 0 \%$ relative humidity ............................... 4

Figure 2. Gel point measurement at (a) $15^{\circ} \mathrm{C}$, (b) $22.5^{\circ} \mathrm{C}$, and (c) $30^{\circ} \mathrm{C} \ldots \ldots \ldots \ldots \ldots \ldots \ldots . . . . .5$

Figure 3. Butt tensile strength of Wilethane 44 on Aluminum Substrates

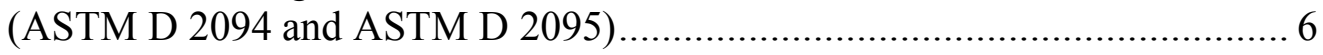

Figure 4. Bulk Wilethane 44 samples cured for the designed experiment...................... 7

Figure 5. Density contours of Wilethane 44: (a) measured, and (b) predicted................ 8

Figure 6. 24-Hour Shore D hardness contours of Wilethane 44: (a) measured and

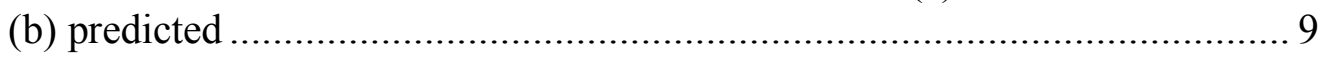

Figure 7. Wilethane 44 Shore D Hardness at $15^{\circ} \mathrm{C}$, showing that cure continues after 24 hours

Figure 8. Maximum allowable relative humidity as a function of temperature, based on a $1 \%$ void volume limitation 


\title{
Effects of Temperature and Humidity on Wilethane 44 Cure
}

\author{
by \\ John C. Weigle \\ Weapons Engineering Technology, Materials Engineering
}

\begin{abstract}
Wilethane 44 is a polyurethane adhesive developed by the Materials Team within ESA-MEE at Los Alamos National Laboratory as a replacement for Hexcel Corporation Urethane 7200. Urethane 7200 is used in numerous weapon systems, but it was withdrawn from the market in 1989. The weapons complex requires a replacement material for use in the W76-1 LEP and the W88, as well as for assembly of JTAs for other warheads.
\end{abstract}

All polyurethane systems are susceptible to moisture reacting with unreacted isocyanate groups. This side reaction competes with the curing reaction and results in $\mathrm{CO}_{2}$ formation. Therefore, a polyurethane adhesive can exhibit foaming if appropriate environmental controls are not in place while it cures. A designed experiment has been conducted at TA-16-304 to determine the effects of ambient conditions on the properties of cured Wilethane 44 . Temperature was varied from $15^{\circ} \mathrm{C}$ to $30^{\circ} \mathrm{C}$ and relative humidity from $15 \%$ to $40 \%$. The density, hardness at 24 hours, and butt tensile strength on aluminum substrates were measured and fitted to quadratic equations over the experimental space. Additionally, the loss and storage moduli during cure were monitored as a function of cure temperature.

These experiments provide a stronger basis for establishing appropriate environmental conditions and cure times when using Wilethane 44. The current guidelines are a working time of 90 minutes, a cure time of 18 hours, and a relative humidity of less than $25 \%$, regardless of ambient temperature. Viscosity measurements revealed that the working time is a strong function of temperature and can be as long as 130 minutes at $15^{\circ} \mathrm{C}$ or as short as 90 minutes at $30^{\circ} \mathrm{C}$. The experiments also showed that the gel time is much longer than originally thought, as long as 13 hours at $15^{\circ} \mathrm{C}$. Consequently, it may be necessary to extend the required cure time at temperatures below $20^{\circ} \mathrm{C}$. Allowable humidity varies as a function of temperature from $34 \%$ at $15^{\circ} \mathrm{C}$ to $15 \%$ at $30^{\circ} \mathrm{C}$.

\section{Introduction}

Hexcel Corporation Urethane 7200 has been used in bonding operations at the BWXT Pantex Plant and at Los Alamos National Laboratory since 1975. It is used to bond detonator locators into the W88 main high explosive charges; booster pellets into main HE charges in the B61, W76, and W80; and may be used to repair HE charges. Urethane 7200 is also used in special test assemblies at Los Alamos. The last order for Urethane 7200 was received in 1989.

Wilethane 44 was formulated as a drop-in replacement, as similar as possible to Urethane 7200 . Wilethane 44 is a controlled formula with a known and consistent 
chemical composition, formulated from readily available commercial materials.

The prepolymer (Part A) consists of $91.8 \%$ by weight Dow Isonate ${ }^{\circledR} 181$, an MDI reacted with polypropylene glycol, $2.0 \%$ by weight Dow P425 polyproplylene glycol, and $6.2 \%$ by weight BASF PolyTHF ${ }^{\circledR} 650$. The curing agent (Part B) is Bayer Multranol ${ }^{\circledR} 4012$, a trifunctional polyol. Parts A and B are formulated at the Honeywell FM\&T Kansas City Plant. A comparison of the torsional shear, hardness, bond strength, and pot life properties between both adhesives show Wilethane 44 to have similar or improved properties to Urethane 7200 . Wilethane 44 has also undergone testing for compatibility with high explosives through differential scanning calorimetry and vacuum thermal stability. Limited long-term compatibility testing has also been completed. In all cases, Wilethane 44 showed superior performance to Urethane $7200 .^{1-4}$

One limitation common to all polyurethane adhesives is their sensitivity to moisture. The generic cure chemistry for hydroxy-cured polyurethanes is shown below.

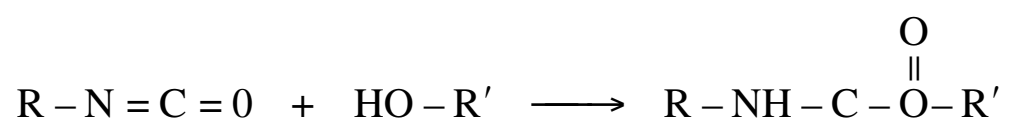

$\mathrm{R}$ and $\mathrm{R}$ ' represent general organic groups, and the $\mathrm{N}=\mathrm{C}=\mathrm{O}$ group is known as an isocyanate. Isocyanate groups can also react with moisture, forming an amine, $\mathrm{R}_{-} \mathrm{NH}_{2}$, and carbon dioxide. The release of carbon dioxide can cause bubbles within the polyurethane. This side reaction can occur with all polyurethane adhesives, including Urethane 7200. It has become a more significant issue with Wilethane 44 because of new applications for the adhesive.

Because of its moisture sensitivity, it is necessary to establish limits on the environmental conditions under which Wilethane 44 can be used. The initial requirement, that the relative humidity must be less than $25 \%$, was based on observations during the material development efforts. A designed experiment has now been completed that allows more rigorous definition of the environmental limits. Wilethane 44 was cured for 24 hours under temperatures ranging from $15^{\circ} \mathrm{C}$ to $30^{\circ} \mathrm{C}$ and relative humidities ranging from $15 \%$ to $40 \%$. Bulk density, hardness at 24 hours, and butt tensile strength on aluminum substrates were all measured then fitted with quadratic equations to show the effect of temperature and humidity. Bulk density, which is a function of the void volume, was the property most sensitive to the environmental conditions. Therefore, the maximum allowable void volume was selected to be $1 \%$. From that, the bulk density could be calculated and a relationship established between allowable relative humidity and temperature. Under the new proposed limits, allowable humidity varies from $34 \%$ at $15^{\circ} \mathrm{C}$ to $15 \%$ at $30^{\circ} \mathrm{C}$.

\section{Experimental}

The Wilethane 44 used in these experiments was from lot \#030715 (Part A) and lot \#2010-071603 (Part B). These lots were made at the FM\&T Honeywell Kansas City Plant on July 15, 2003 (Part A) and July 16, 2003 (Part B). The materials underwent reacceptance testing at the Kansas City Plant on 12/12/05 (Part A) and 7/12/05 (Part B) and had expiration dates of June 12, 2006 (Part A) and July 20, 2006 (Part B). All testing described in this report was completed by May 31, 2006. The mixed adhesive was 
prepared by dispensing it from a 1:1 volumetric ratio dual-chamber cartridge through a 20 stage static mixer. The adhesive components were deaerated after they were loaded into the cartridge, but they were not deaerated after flowing through the static mixer.

Rheological measurements were made on a Rheometric Scientific ARES rheometer. The instrument includes a convection-type environmental chamber capable of operating from $-150^{\circ} \mathrm{C}$ to $600^{\circ} \mathrm{C}$. The humidity within the chamber was not controlled. However, the chamber was fed nitrogen gas from a liquid nitrogen dewar, resulting in essentially $0 \%$ relative humidity. Adhesive was placed between two parallel $25 \mathrm{~mm}$ disks with a gap of $\sim 1 \mathrm{~mm}$. The storage and loss moduli were measured in dynamic frequency sweep tests at $\omega=1.0 \mathrm{rad} / \mathrm{s}$. The tests were stopped after the gel point was reached $\left(\mathrm{G}^{\prime}=\mathrm{G}^{\prime \prime}\right)$. In addition to measuring the gel time, the working time can also be defined from these measurements. Working time is a subjective quantity that is application dependent. It is commonly defined as the time for the viscosity to reach either 80 or $100 \mathrm{~Pa}$-s.

A two-factor, three-level designed experiment was conducted to investigate the effects of temperature and humidity on the properties of cured Wilethane 44. Samples were cured in a Cincinnati Sub-Zero ZH-16-2 environmental chamber. The chamber can operate between $-34^{\circ} \mathrm{C}$ and $190^{\circ} \mathrm{C}$ and $10 \%$ to $95 \%$ relative humidity. However, the system is also limited to a minimum wet bulb temperature of $4^{\circ} \mathrm{C}$, according to the manufacturer's specifications. In practice, the chamber operated reliably when the wet bulb temperature was as low as $-10^{\circ} \mathrm{C}$. This corresponds to approximately $15 \% \mathrm{RH}$ at $15^{\circ} \mathrm{C}$, which established the lower humidity limit of the experimental design. The upper humidity limit, $40 \%$, was established based on previous experience with Wilethane 44 . The temperature range was selected based on the temperatures within the assembly cells at the BWXT Pantex plant. The cells can be as low as $60^{\circ} \mathrm{F}\left(15.6^{\circ} \mathrm{C}\right)$. There is no upper limit, although operations typically cease whenever the temperature exceeds $85^{\circ} \mathrm{F}\left(29.4^{\circ} \mathrm{C}\right)$.

Two types of samples were prepared in the environmental chamber: aluminum butt tensile samples ${ }^{5-6}$ and $22 \mathrm{~mm} \times 22 \mathrm{~mm} \times 10 \mathrm{~mm}$ blocks used to measure 24-hour hardness and bulk density. The aluminum substrates were cleaned with acetone then treated in an air plasma for 20 minutes before bonding. Six replicate samples were prepared at each condition. In addition to the samples for the designed experiment, several baseline density and hardness samples were prepared at $0 \% \mathrm{RH}$ in a small desiccator that was placed into the environmental chamber.

Butt tensile experiments were conducted on an Instron 5500R test frame. The frame was equipped with a $10 \mathrm{kN}$ load cell, last calibrated on July 20, 2005, with an expiration date of July 20, 2007 (LANL calibration file \#031485). The butt tensile samples were pulled at a constant extension rate of $2 \mathrm{~mm} / \mathrm{min}$. The maximum load was recorded, and the average stress at fracture was calculated.

The 24-hour hardness was measured using a Shore D durometer. ${ }^{7}$ In addition to the hardness at 24 hours, the change in hardness as a function of time was measured over 72 hours for samples prepared at $15^{\circ} \mathrm{C}$ and $0 \%$ relative humidity. This experiment was necessary because the material had not completely cured at 24 hours at $15^{\circ} \mathrm{C}$.

The blocks were also used to measure the bulk density of the cured material and compare it with the true density. Samples with minimal bubbles were prepared by curing the adhesive blocks at $0 \%$ humidity and $22.5^{\circ} \mathrm{C}$. The density of these samples was considered 
to be the true density of cured Wilethane 44. Any bubbles trapped in the samples when cured at higher humidity cause the bulk density to drop, and the void fraction can be established from the ratio of the bulk and true densities. Bulk density was measured by hydrostatic weighing. ${ }^{8}$

\section{Results}

The rheological measurements reveal a significant temperature dependence for both the working time and the gel time of Wilethane 44 . The viscosity curves are shown in Figure 1. If the working time is defined as the time to reach $100 \mathrm{~Pa}-\mathrm{s}$, then it decreases from 134 minutes at $15^{\circ} \mathrm{C}$ to 93 minutes at $30^{\circ} \mathrm{C}$. The precise working time is application specific because some applications permit the use of more viscous adhesive.

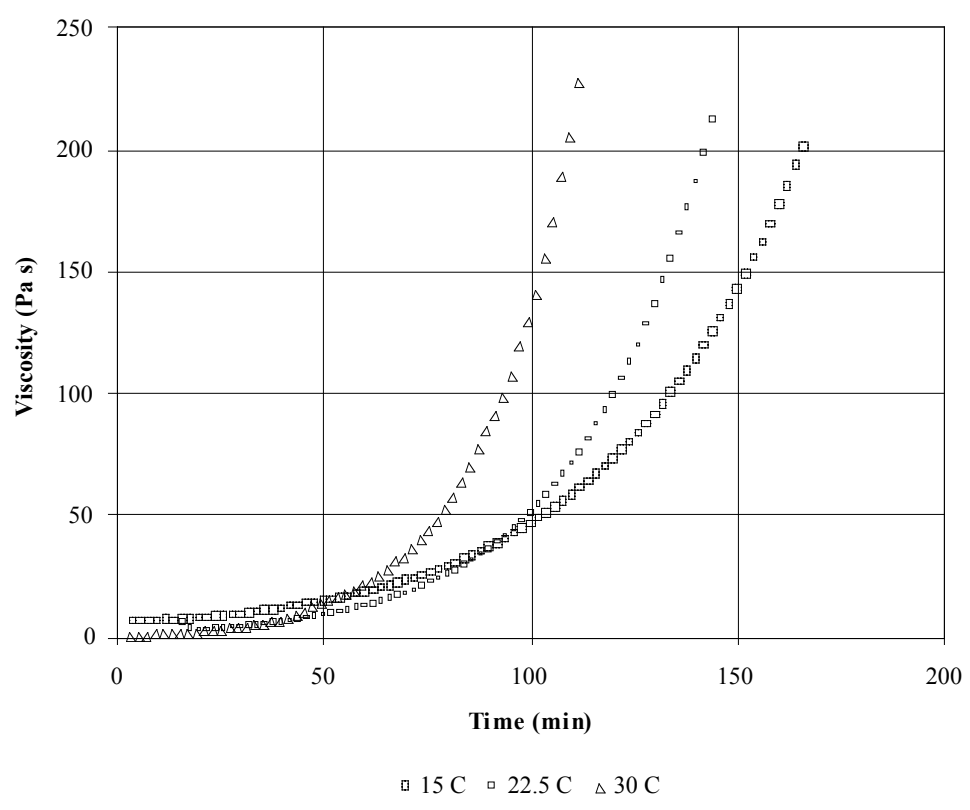

Figure 1. Cure curves for Wilethane 44 at $\sim 0 \%$ relative humidity.

Perhaps more surprising are the long gel times that were observed, as seen in Figures 2(a)-(c). The gel times ranged from 7.0 hours at $30^{\circ} \mathrm{C}$ to 13.3 hours at $15^{\circ} \mathrm{C}$. The long gel time at $15^{\circ} \mathrm{C}$ may indicate that longer cure times are required at low temperatures.

Figure 3 shows the results of the tensile tests. The variability of the individual measurements is quite large relative to any changes caused by temperature or humidity during cure. This degree of variability is not unusual for the test because the adhesive strength can be affected by many subtle factors. The standard deviation of the measurements on the six specimens cured at any given condition was approximately 600 psi. Aside from the single point at $22.5^{\circ} \mathrm{C}$ and $40 \% \mathrm{RH}$, the average strengths were all within two standard deviations of each other. Therefore, no definite conclusions can be drawn. There may be a slight increase in tensile strength at higher humidity, but it would be necessary to test many more samples to establish the statistical significance of this apparent trend. 


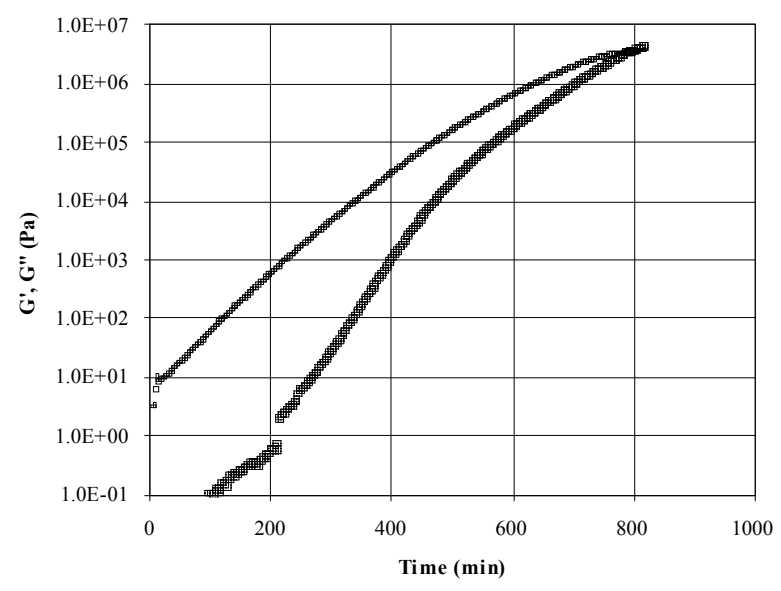

(a)

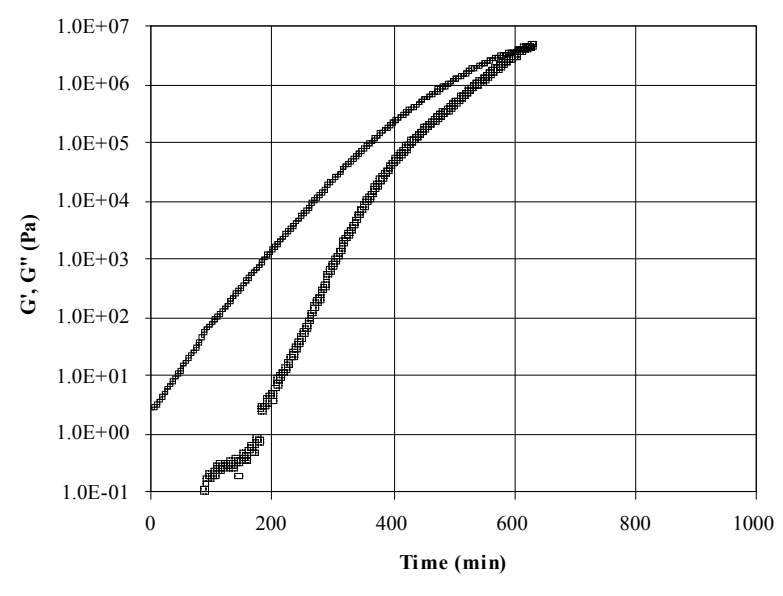

口 $\mathrm{G}^{\prime} \circ \mathrm{G}^{\prime \prime}$

(b)

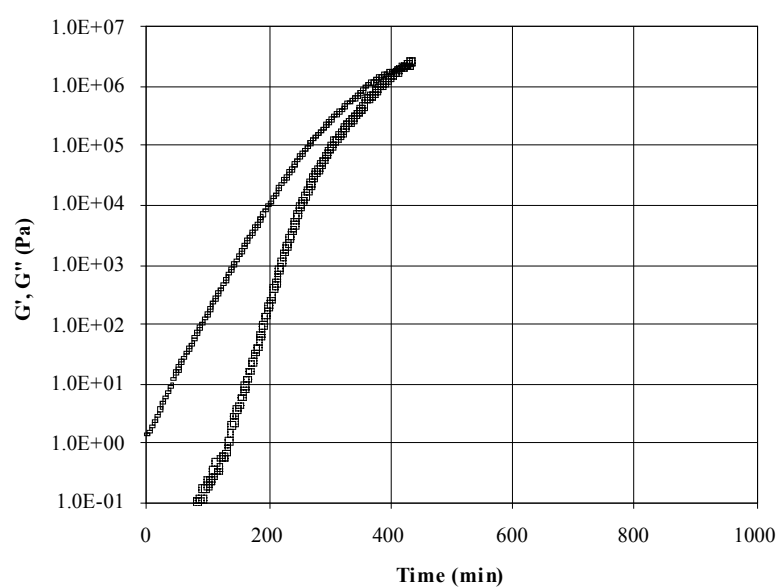

$\square G^{\prime} \square G^{\prime \prime}$

(c)

Figure 2. Gel point measurement at (a) $15^{\circ} \mathrm{C}$, (b) $22.5^{\circ} \mathrm{C}$, and (c) $30^{\circ} \mathrm{C}$. 


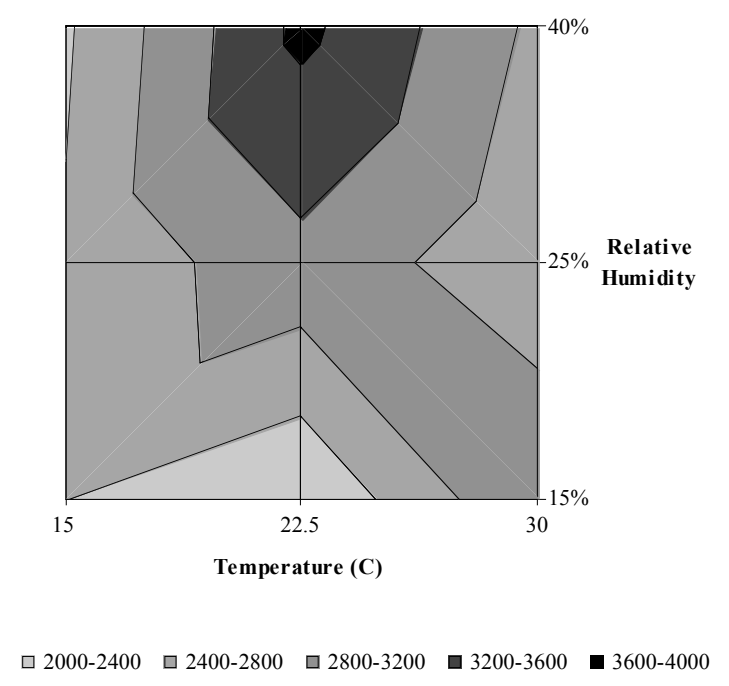

Figure 3. Butt tensile strength of Wilethane 44 on Aluminum Substrates (ASTM D 2094 and ASTM D 2095).

Figure 4 shows the Wilethane 44 blocks. As expected, the amount of bubbling increases as the relative humidity increases at a constant temperature. It is also apparent that the amount of bubbling increases as the temperature increases at a constant relative humidity. This result is not too surprising because the absolute water content of the atmosphere increases, even though the relative humidity remains constant. The degree of bubbling is quantified by the bulk density of the blocks. Figure 5(a) shows the results of the density measurements. Bulk density varies from a low of $1.117 \mathrm{~g} / \mathrm{cm}^{3}$ at $30^{\circ} \mathrm{C}$ and $40 \% \mathrm{RH}$ to $1.163 \mathrm{~g} / \mathrm{cm}^{3}$ at $15^{\circ} \mathrm{C}$ and $15 \% \mathrm{RH}$. The baseline density, material cured at $22.5^{\circ} \mathrm{C}$ and $0 \% \mathrm{RH}$, is $1.165 \mathrm{~g} / \mathrm{cm}^{3}$. When fit with a quadratic equation, the bulk density can be predicted by

$\rho=-1.7 \times 10^{-4} \mathbf{T}^{2}-7.9 \times 10^{-5} \mathbf{T} * \mathbf{R H}+1.5 \times 10^{-5} \mathbf{R} \mathbf{H}^{2}+8.4 \times 10^{-3} \mathbf{T}+1.09$,

where $\rho$ is in $\mathrm{g} / \mathrm{cm}^{3}, \mathbf{T}$ is in ${ }^{\circ} \mathrm{C}$, and $\mathbf{R H}$ is in percent. Figure $5(\mathrm{~b})$ provides a comparison between the measured and predicted densities. The agreement is not perfect, but the overall contour is captured by the quadratic fit. The most significant deviations occur at $15^{\circ} \mathrm{C}$. The deviations are likely due to the fact that the designed experiment serves primarily as a screening tool. A more precise model could be developed if additional samples were prepared in this region of the experimental space.

The 24-hour hardness of the samples is not visually apparent from the samples. However, Figure 6(a) shows that temperature significantly affects the 24-hour hardness. Relative humidity has a slight influence. Hardness varies from a low of 60.1 at $15^{\circ} \mathrm{C}$ and $40 \% \mathrm{RH}$ to 77.8 at $30^{\circ} \mathrm{C}$ and $15 \% \mathrm{RH}$. When fit with a quadratic equation, the Shore $\mathrm{D}$ hardness can be predicted by:

$$
\mathbf{H}=-0.113 \mathbf{T}^{2}-0.014 \mathbf{T} * \mathbf{R H}+0.0064 \mathbf{R} \mathbf{H}^{2}+6.59 \mathbf{T}-12.3,
$$


where $\mathbf{H}$ is Shore D hardness, $\mathbf{T}$ is in ${ }^{\circ} \mathrm{C}$, and $\mathbf{R H}$ is in percent. Figure $6(\mathrm{~b})$ provides a comparison between the measured and predicted hardness. The quadratic model fits the data very well.

The low 24-hour hardness measured at $15^{\circ} \mathrm{C}$ is due to slower cure kinetics and not due to inherent differences in the properties of the cured material. To show this, the hardness of Wilethane 44 was monitored at $15^{\circ} \mathrm{C}$ beyond 24 hours. The results are shown in Figure 7. It can be seen that the ultimate hardness reaches $\sim 75$, which is the same as for material cured at higher temperatures. However, it takes about 36 hours for the hardness to approach its ultimate value. It should be noted that, even though the hardness has not achieved its ultimate value at 24 hours, the material still possesses significant tensile strength at that time.

\section{Establishing Environmental Conditions for Wilethane 44 Use}

The results of the designed experiment provide a strong basis for establishing appropriate limits on the environmental conditions under which Wilethane 44 can be used. It was decided to allow $1 \%$ void volume within the cured material. Obviously, this selection is somewhat arbitrary and the true void fraction that will develop during cure depends on sample geometry. Using this as the criterion, the minimum bulk density can be calculated as $1.153 \mathrm{~g} / \mathrm{cm}^{3}$. Plugging this density into Eq. (2) gives the following:

$$
\begin{aligned}
0=1.5 \times 10^{-5} \mathbf{R H}^{2}+\left(-7.9 \times 10^{-5} \mathbf{T}\right) \mathbf{R H} \\
+\left(-1.7 \times 10^{-4} \mathbf{T}^{2}+8.4 \times 10^{-3} \mathbf{T}+1.09-1.153\right) .
\end{aligned}
$$

At any given temperature between $15^{\circ} \mathrm{C}$ and $30^{\circ} \mathrm{C}$, Eq. (4) is a quadratic equation in $\mathbf{R H}$ that can be solved for its roots. The lesser root is the one of interest for this analysis.

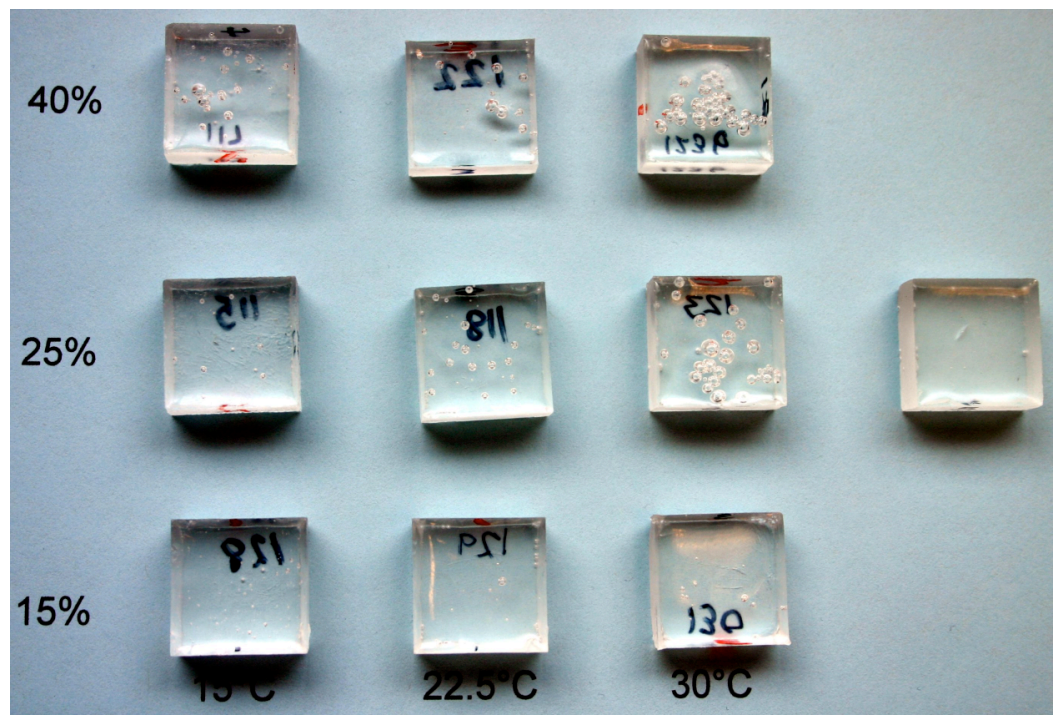

Figure 4. Bulk Wilethane 44 samples cured for the designed experiment. The baseline material, cured at $22.5^{\circ} \mathrm{C}$ and $0 \% \mathrm{RH}$ is shown on the far right. 


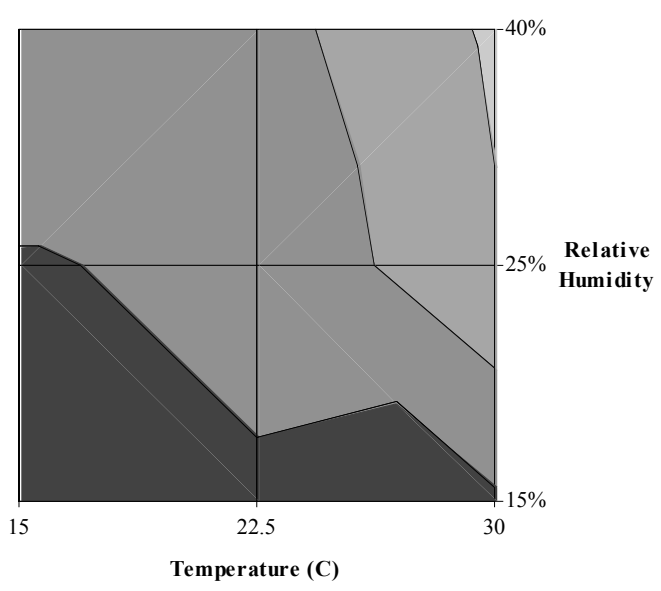

$\square 1.1-1.12 \square 1.12-1.14 \quad \square 1.14-1.16 \quad \square 1.16-1.18$

(a)

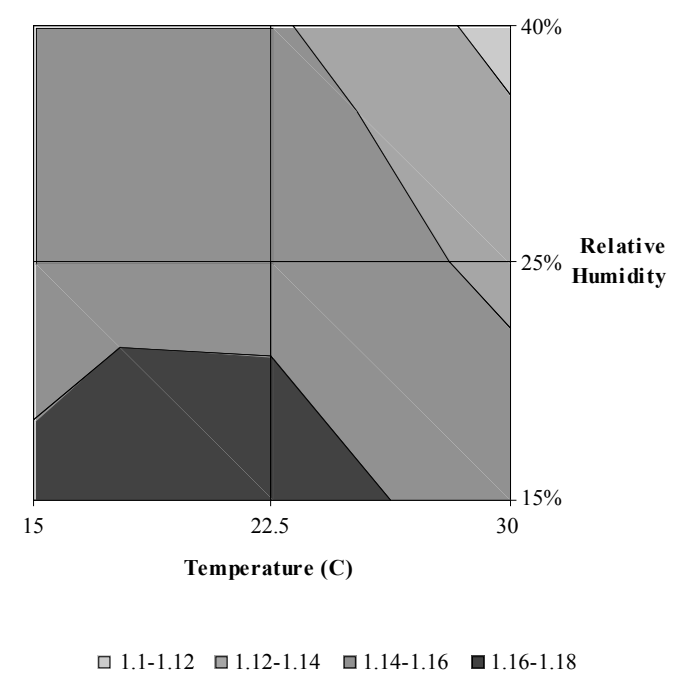

(b)

Figure 5. Density contours of Wilethane 44: (a) measured, and (b) predicted. 


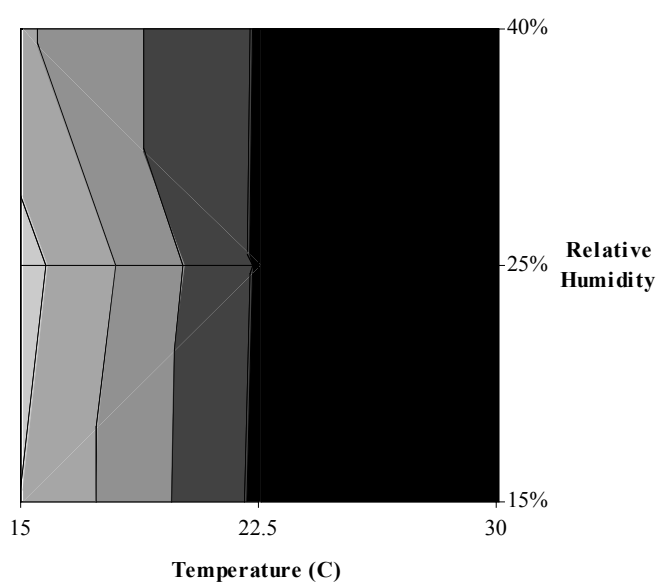

$\square 55-60 \square 60-65 \square 65-70 \square 70-75 \square 75-80$

(a)

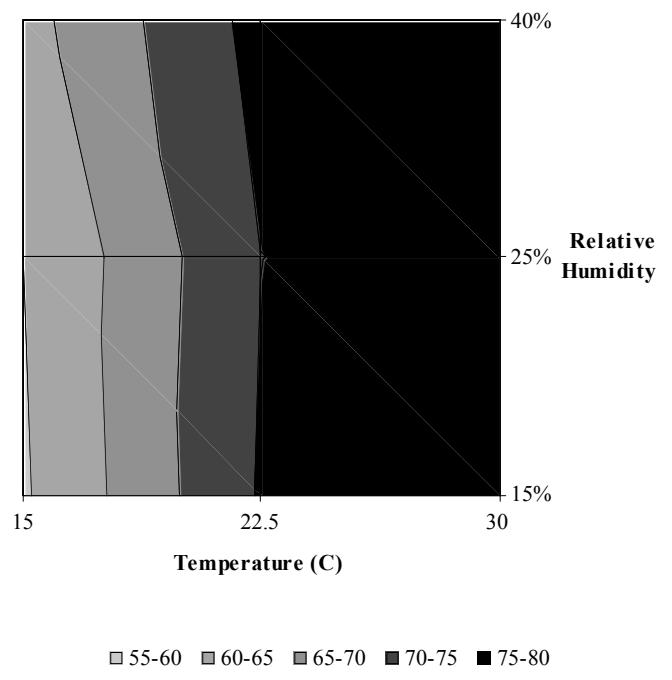

(b)

Figure 6. 24-Hour Shore D hardness contours of Wilethane 44: (a) measured and (b) predicted. 


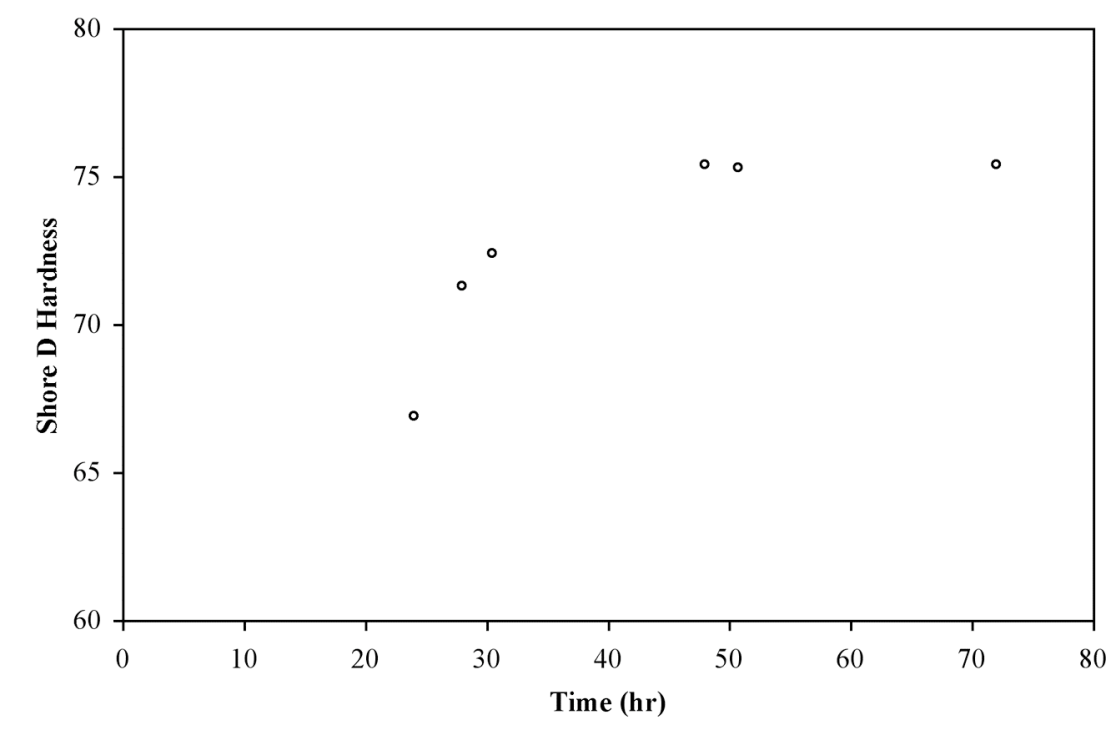

Figure 7. Wilethane 44 Shore D Hardness at $15^{\circ} \mathrm{C}$, showing that cure continues after 24 hours.

It is critical to realize that this equation is purely empirical and cannot be applied outside the limits of $15^{\circ} \mathrm{C}$ to $30^{\circ} \mathrm{C}$ and $15 \%$ RH to $40 \% \mathrm{RH}$. When the equation is solved for $\mathbf{R H}$ as a function of $\mathbf{T}$, the limits shown in Figure 8 result. These are the proposed new limits for using Wilethane 44 . In fact, at $15^{\circ} \mathrm{C}$, the calculated allowable relative humidity decreases slightly to $32.7 \%$. This decrease does not make physical sense; it is purely a result of the quadratic data fit. Therefore, the allowable relative humidity at $15^{\circ} \mathrm{C}$ was set to be equal to the calculated value at $16^{\circ} \mathrm{C}$.

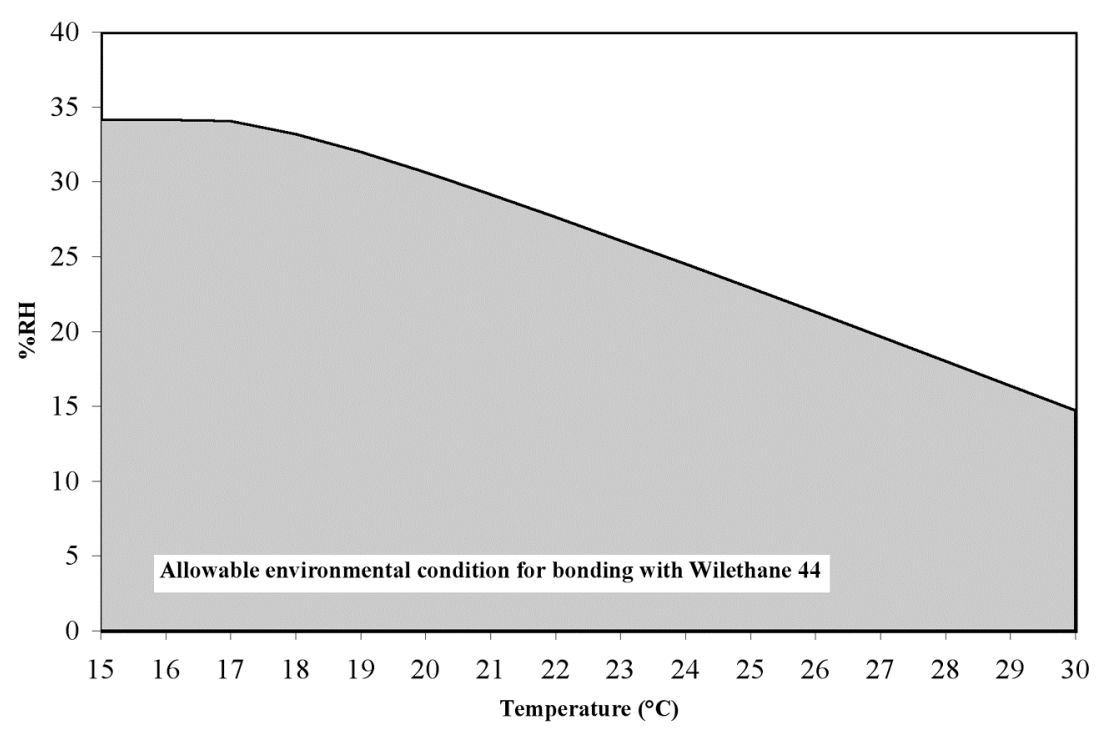

Figure 8. Maximum allowable relative humidity as a function of temperature, based on a $1 \%$ void volume limitation. 


\section{Conclusions}

Wilethane 44 has previously been shown to be a superior replacement to Urethane 7200 in terms of hardness, pot life, compatibility with high explosives, tensile strength, and torsional shear. However, the effects of ambient conditions during the curing process had not been well characterized. Rheological measurements and a designed experiment have been completed to investigate these effects. The working time of the adhesive depends heavily on the cure temperature and ranges from approximately 90 to 130 minutes. Gel times are significantly longer than anticipated and may indicate that longer cure times are required at low temperatures to prevent the creep of bonded components. This effect is also seen in the results of the 24-hour hardness tests.

Finally, both temperature and relative humidity influence the bulk density of the cured material. That effect has been characterized by a quadratic data fit and has been used to establish proposed operational limits on relative humidity as a function of temperature. The recommended allowable humidity when bonding with Wilethane 44 varies from $34 \%$ at $15^{\circ} \mathrm{C}\left(59^{\circ} \mathrm{F}\right)$ to $15 \%$ at $30^{\circ} \mathrm{C}\left(86^{\circ} \mathrm{F}\right)$. These limits are comparable to the $25 \%$ relative humidity limit that had been set previously. However, this work shows how the limit can be increased or decreased by adjusting the temperature at which the bonding occurs.

\section{Acknowledgements}

Many people other than the author participated in these experiments. Diana Honnell (WT-6) prepared and analyzed many of the Wilethane samples. Bart Olinger (WT-5) performed the density measurements. Tom Stephens (WT-6) provided guidance for using the ARES rheometer and analyzing the data collected.

\section{References}

1. Mendoza, D., and Stephens, T., "An Overview of the Development of Wilethane 44 Adhesive," $33^{\text {rd }}$ Annual PolyMAC Conference, Amarillo, Texas, Los Alamos National Laboratory document LA-UR-03-3842 (2003).

2. Weigle, J. C.; Stephens, T.; and Mendoza, D., "Adhesives for Bonding High Explosive Materials," $34^{\text {th }}$ Annual PolyMAC Conference, Albuquerque, New Mexico, Los Alamos National Laboratory document LA-UR-04-3811 (2004).

3. Laintz, K., "Compatibility of Urethane 7200 Adhesive with Selected Explosives," Los Alamos National Laboratory memorandum DX-2:03-178 (2003).

4. Laintz, K., "Compatibility of Wilethane 44 Urethane Adhesive with Selected Explosives," Los Alamos National Laboratory memorandum DX-2:03-169 (2003).

5. ASTM D 2094-00, "Standard Practice for Preparation of Bar and Rod Specimens for Adhesion Tests" (2006).

6. ASTM D 2095-96, "Standard Test Method for Tensile Strength of Adhesives by Means of Bar and Rod Specimens" (2002). 
7. ASTM D 2240-05, "Standard Test Method for Rubber Property—Durometer Hardness" (2005).

8. Olinger, B., "Precise and Accurate Density Determination of Explosives Using Hydrostatic Weighing," Los Alamos National Laboratory report LA-14174 (2005). 
This report has been reproduced directly from the best available copy. It is available electronically on the Web (http://www.doe.gov/bridge).

Copies are available for sale to U.S. Department of Energy employees and contractors from:

Office of Scientific and Technical Information

P.O. Box 62

Oak Ridge, TN 37831

(865) 576-8401

Copies are available for sale to the public from: National Technical Information Service

U.S. Department of Commerce

5285 Port Royal Road

Springfield, VA 22161

(800) 553-6847 
- Los Alamos NATIONAL LABORATORY

EST.1943 